\title{
Ceticismo versus cosmopolitismo: uma análise das perspectivas de Robert Dahl e de David Held sobre o sentido da democracia no contexto da globalização
}

\author{
Alexsandro Eugenio Pereira, Universidade Federal do Paraná, Brasil
}

\begin{abstract}
Resumo: O propósito deste artigo é comparar duas perspectivas analíticas que interpretaram as possibilidades de democratização das organizações internacionais (OIGs) nos anos 1990 e 2000. A primeira dessas perspectivas é sustentada por autores como Robert Dahl e Philippe Schmitter que consideram improvável a realização da democracia fora do espaço dos Estados nacionais. Eles seriam "céticos", para empregar o termo utilizado por Dahl para se referir à sua perspectiva. De outro lado, David Held sustentou uma interpretação mais otimista ao defender que a natureza da democracia contemporânea sofreu alterações resultantes do processo de globalização econômica. Por essa razão, Held considerou possivel tanto a democratização das OIGs como o desenvolvimento de uma "cidadania cosmopolita", situada acima dos limites dos Estados. Para desenvolver o contraponto entre estas duas perspectivas, este artigo realizará uma revisão bibliográfica da produção dos dois autores e estará dividido em duas seções principais. A primeira delas examinará a perspectiva "cética" de Robert Dahl com relação à possibilidade de democratização das organizações internacionais. A segunda seção examinará a perspectiva cosmopolita de David Held. Nas considerações finais, o artigo identificará os elementos de reflexão gerados pelas duas perspectivas a respeito do sentido da democracia no contexto da globalização.
\end{abstract}

Palavras-chave: ceticismo, cosmopolitismo, democracia, organizações internacionais, globalização

\begin{abstract}
The purpose of this article is to compare two analytical perspectives that have interpreted the democratization of the international organizations (IOs) in the years 1990 and 2000. The first of this perspectives is supported by authors such as Robert Dahl and Philippe Schmitter who consider improbable to realize the democracy in the space outside the national States. They are 'skeptical', according to the term employed by Dahl to refer to their perspective. On the other hand, David Held sustained a more optimistic interpretation by advocating that the nature of contemporary democracy suffered changes as result of the economic globalization process. For this reason, Held considered possible the democratization of IOs as well as the development of a 'cosmopolitan citizenship', located above the limits of the States. To develop the counterpoint between this two perspectives, this article will carry out a literature review of the production of the two authors and will be divided into two main sections. The first one will examine the prospect 'skeptical' of Robert Dahl regarding the possibility of democratization of international organizations. The second section examines the cosmopolitan perspective from David Held. In concluding remarks, the article identifies the elements of reflection generated by two perspectives concerning the sense of democracy in the context of globalization.
\end{abstract}

Keywords: Skepticism, Cosmopolitanism, Democracy, International Organizations, Globalization

\section{Introdução}

A análise teórica da democracia contemporânea envolveu dois conceitos que dominam os debates sobre a qualidade das instituições nos meios políticos e acadêmicos: transparência e accountability. Esses dois conceitos estão associados, pois instituições políticas mais transparentes ou que desenvolvem mecanismos de transparência tornam-se mais suscetíveis à avaliação dos atores sociais interessados tanto no comportamento dessas instituições, como dos indivíduos responsáveis pela tomada de decisões dentro delas. Accountability pode ser definida como a responsabilização dos agentes públicos perante os cidadãos. Por meio de mecanismos de accountability, como os processos eleitorais e os tribunais de contas, os agentes públicos são submetidos a formas de controle, exercidas por instituições políticas específicas ou pela capacidade de avaliação dos cidadãos no momento em que participam do processo eleitoral por meio do voto. A transparência, por sua vez, é compreendida como um elemento chave para tornar as instituições e os agentes polí- 
ticos mais responsáveis perante a sociedade e, especialmente, perante aqueles que precisam lidar com as consequências das decisões políticas tomadas por esses agentes. O tema da transparência é, no entanto, mais amplo e envolve, também, organizações não governamentais, empresas privadas, bancos e outros atores coletivos cuja atividade tem impactos ambientais, sociais, econômicos e culturais. Tornou-se comum o desenvolvimento de mecanismos de transparência nos setores público e privado em diversas partes do mundo. Nesse contexto, as organizações internacionais são pressionadas a desenvolver mecanismos de transparência com o propósito de tornar visíveis suas atividades e a forma como utilizam recursos fornecidos pelos Estados nacionais. Por vezes, o próprio debate interno e o processo decisório são disponibilizados por meio de mecanismos de acesso às informações. No momento atual, as organizações internacionais são criticadas por Estados, por ONGs (Organizações não-Governamentais), pela mídia, pelos analistas internacionais, dentre outros, que apontam a necessidade de reforma-las para torna-las mais representativas, mais legítimas e mais responsáveis perante as populações afetadas por suas decisões.

A transposição do debate sobre a qualidade da democracia para o âmbito internacional é complexo. Diferentes autores, como Ruth Grant e Robert Keohane (2005) e Andrew Moravscik (2004), por exemplo, apontaram as dificuldades inerentes à democratização das organizações internacionais, o que inclui o desenvolvimento de mecanismos de transparência e de accountability. O ponto de partida para pensar essas dificuldades, de acordo com Grant e Keohane, diz respeito à ausência de eleitores na política internacional perante os quais às organizações internacionais poderiam ser responsáveis. Os eleitores estão situados no âmbito doméstico e, por natureza, a política internacional é caracterizada pela ausência de governo e pela presença decisiva dos Estados como atores fundamentais. Por essa razão, a tarefa de avaliar as possibilidades de realização da democracia fora do âmbito doméstico dos Estados nacionais torna-se complexa. Seriam as organizações internacionais responsáveis perante os Estados, que são seus principais financiadores? Ou essas organizações podem ser responsáveis, também, perante outros atores não-estatais, como as ONGs e os movimentos sociais transnacionais? Ou, ainda, seria possível pensar a responsabilização das organizações internacionais perante as populações afetadas por suas decisões? Ou, em síntese, será que as organizações internacionais podem ser (ou se tornar) democráticas? Ou a democracia só encontra condições de se desenvolver dentro dos Estados nacionais?

Duas respostas a essas questões podem ser identificadas na literatura que avalia a democracia na política internacional. A primeira resposta foi apresentada por Robert Dahl em dois artigos publicados em momentos diferentes (1994 e 1999). No artigo publicado em 1999, intitulado "Can International Organizations be Democratic? A Skeptic's View", Dahl desenvolve uma perspectiva denominada por ele mesmo de "cética" com relação às possibilidades de realização da democracia fora do espaço doméstico dos Estados. O ceticismo de Dahl fundamenta-se, num primeiro momento, numa análise sobre o significado de democracia. Dahl considera que existe um uso indiscriminado do termo democracia no debate acadêmico e público. Definir o que é democracia, diz Dahl, é mais difícil do que parece sugerir esse debate. Retomaremos esse ponto na primeira seção do artigo. A segunda resposta, por sua vez, foi formulada no âmbito do cosmopolitismo de David Held, que analisou as consequências da globalização sobre o desenvolvimento da democracia no contexto contemporâneo. O argumento de Held é de que a democracia sofreu alterações resultantes do processo de globalização, gerando um deslocamento do locus da decisão política dos Estados nacionais para as organizações internacionais e supranacionais.

Partindo dessas duas respostas possíveis, a do ceticismo de Dahl e a do cosmopolitismo de Held, este artigo tem como objetivo estabelecer um contraponto entre essas duas perspectivas, examinando em que medida elas fornecem condições para uma avaliação das tentativas de democratização da política internacional. Para desenvolver o contraponto entre as duas perspectivas, o artigo realizará uma revisão bibliográfica da produção dos dois autores e estará dividido em duas seções principais, além das considerações finais. A primeira delas examinará a perspectiva "cética" de Robert Dahl com relação à possibilidade de democratização das organizações internacionais. A segunda examinará a perspectiva cosmopolita de David Held. Nas considerações finais, o artigo 
identificará elementos de reflexão gerados pelas duas perspectivas a respeito do sentido da democracia no contexto da globalização.

Nesse artigo argumentaremos que as duas perspectivas levantam questões importantes para pensar as possibilidades de democratização das organizações internacionais, embora o ceticismo de Dahl resulte numa afirmação peremptória segundo a qual as OIGs (Organizações Intergovernamentais) não podem ser democráticas. Tentaremos expor essas possibilidades, reconhecendo as dificuldades inerentes a qualquer reflexão sobre a democracia no contexto da globalização. Dificuldades que se tornaram maiores quando examinamos a democracia no âmbito internacional contemporâneo.

\section{A perspectiva "cética" de Robert Dahl}

Robert Dahl expressou seu ceticismo sobre as possibilidades da democracia no âmbito internacional em, pelo menos, dois artigos publicados nos anos 1990. No primeiro deles, Dahl (1994) estava interessado nas consequências do Tratado de Maastricht (1992) $)^{1}$ para a formação da União Europeia. Nesse artigo, Dahl examinou os arranjos institucionais estabelecidos na Europa integrada, responsáveis pela inserção dos governos nacionais dentro de um sistema transnacional mais amplo e menos democrático segundo ele. O desenvolvimento de instituições políticas supranacionais e intergovernamentais, dotadas de capacidade decisória, gerou o dilema fundamental da democracia contemporânea nos termos do autor: de um lado, cidadãos dos países podem preservar a autoridade política e democrática nacional e, por consequência, manter sua capacidade de influenciar a conduta dos governos nacionais, mesmo reconhecendo a existência de assuntos importantes frente aos quais seus governos não têm capacidade de gerar soluções de forma eficaz; por outro, os cidadãos nacionais podem fortalecer uma unidade política maior e transnacional capaz de lidar melhor com temas que transcendem os limites dos Estados nacionais, mesmo que isso implique na redução de sua capacidade de influenciar o comportamento das instituições políticas intergovernamentais e supranacionais dessa unidade. O dilema, no entanto, não é exclusividade do processo de integração europeu dos anos 1990 em diante. É um dilema presente no contexto da globalização no qual indivíduos se defrontam com influências externas capazes de afetar suas vidas cotidianas, embora tais influências escapem do controle dos Estados nacionais (cf. Dahl, 1994, p. 24). Essas influências, por sua vez, podem ser resultantes das decisões tomadas pelos Estados no momento em que optam por participar de processos de integração ou quando desenvolvem regimes e organizações internacionais. Nesses casos, Estados aceitam limitar sua autonomia em temas específicos quando percebem a possibilidade de obter vantagens econômicas e políticas por meio da cooperação com outros Estados utilizando regimes e organizações ou participando de processos de integração. As influências externas incluem, também, os acontecimentos decorrentes da crescente interdependência econômica e política (ou a globalização) existente no atual contexto internacional. Em outros termos, as influências externas resultantes de processos de integração ou de constrangimentos impostos por regimes e organizações são consequências de opções deliberadas dos Estados nacionais. No que se refere à interdependência econômica e política, é importante notar que ela produz efeitos independentes da vontade dos Estados nacionais.

Dahl compreende, de forma correta, que a globalização afeta os países em variados graus, embora reconheça a necessidade de se observar como atores e forças externas podem limitar as opções disponíveis para os cidadãos localizados em diversos países, mesmo nas grandes potências, como os Estados Unidos. No momento em que ele escreve (início dos anos 1990), o desenvolvimento de instituições políticas intergovernamentais e supranacionais no interior do principal processo de integração está em curso e indica mudanças importantes na própria natureza e no escopo das democracias. Essas

\footnotetext{
${ }^{1}$ O Tratado de Maastricht foi aprovado no dia $01^{\circ}$ de novembro de 1993. Seu propósito foi preparar as condições necessárias para o estabelecimento da União monetária europeia e introduzir alterações para a união política entre os Estados europeus. O Tratado estabeleceu, entre outras coisas, o procedimento de co-decisão pelo qual o Parlamento europeu passou a ter mais peso no processo decisório do bloco. O Parlamento europeu é formado por representantes dos países do bloco eleitos democraticamente. Ele se diferencia de outras instituições do bloco, como o Conselho Europeu, que tem uma natureza intergovernamental. O Conselho Europeu é composto pelos Chefes de Estado dos países da União Europeia. Informações sobre o Tratado e a arquitetura institucional do bloco podem ser encontradas no site da União Europeia. Cf. União Europeia, 2014.
} 
mudanças levam Dahl a considerar a existência de uma terceira fase relativa à transformação histórica da democracia, denominada por ele de "transnacionalização da democracia". A primeira fase correspondeu à democracia da primeira metade do século V a.C., na Grécia. Nessa fase, a democracia era circunscrita a cidade-estado, reaparecendo mais tarde nas cidades-estados da Itália do Renascimento, como Florença e Veneza. A segunda fase envolveu uma transformação de escala na medida que a democracia saiu das cidades-estados e desenvolveu-se no interior do Estado-nação. Correspondeu à passagem da democracia direta de Atenas para a democracia representativa da modernidade. A transição entre a primeira e a segunda fases envolveu, também, a emergência de instituições e práticas políticas desconhecidas na teoria e na prática das cidades-estados, tais como: controle das decisões do governo; eleições realizadas com frequência para a escolha dos eleitos; os adultos passaram a ter direito de voto e a poderem concorrer aos cargos eletivos do governo; os cidadãos passaram a se expressar livremente sobre assuntos políticos sem risco de sofrer punições, pois desfrutaram do direito de buscar fontes alternativas de informação; e os cidadãos formaram associações relativamente independentes, incluindo partidos e grupos de interesse (cf. Dahl, 1994, pp. 25-26). Essas instituições e práticas permanecem no final do século XX, embora a democracia esteja passando por uma nova transformação decorrente do desenvolvimento de sistemas políticos transnacionais como pode ser observado na União Europeia. Esses sistemas transnacionais tendem a gerar redução e perda de autonomia política, econômica, social e cultural dos Estados nacionais. Internamente, os cidadãos nacionais não poderão mais recorrer apenas aos seus governos nacionais ou locais para solicitar um controle direto sobre atores e forças externas que afetam suas vidas. Instituições políticas supranacionais, como o Parlamento europeu, podem se tornar o locus da decisão política sobre temas importantes que afetam a vida dos cidadãos nacionais ${ }^{2}$.

Essa transformação da democracia está em curso e não se completou, mesmo no contexto dos anos 2000 e 2010. Para Dahl, ela envolveu um grande aumento de escala do sistema político com consequências importantes: trata-se de uma transição de sistemas políticos nacionais para sistemas políticos transnacionais. A transnacionalização da democracia gerou, para Dahl, duas consequências: (i) a perda de capacidade dos cidadãos de exercerem controle democrático sobre as decisões políticas; (ii) a redução da capacidade do sistema político de responder, de forma adequada, às preferências coletivas de seus cidadãos. Essas consequências sugerem a necessidade de criação de novas instituições políticas distintas das nacionais. Ele não pretende sugerir como seriam essas instituições. Seu propósito é compreender os efeitos da "transnacionalização da democracia" sobre a capacidade de participação dos cidadãos na tomada de decisões políticas. Mas Dahl não se exime de fazer duas considerações sobre como seriam as instituições políticas transnacionais. Em primeiro lugar, ele considera que elas serão variadas e tomarão decisões sobre diversas questões (econômicas, ambientais, de segurança, dentre outras). Em segundo lugar, exigirão considerável nível de delegação de poder para tomar decisões, fortalecendo funcionários que provavelmente não serão eleitos, mas estarão subordinados aos políticos eleitos democraticamente no plano doméstico.

Dahl considerou que a transnacionalização da democracia agravaria um problema existente nas democracias representativas dos Estados nacionais: o aumento da distância entre cidadãos e instituições políticas. As democracias representativas apresentam uma limitação objetiva que restringe a participação dos cidadãos. Essa limitação diz respeito ao número de indivíduos que desejam influenciar o processo decisório. Não é possível submeter todos os assuntos que são objetos de decisão política a plebiscitos ou referendos. Por isso, as democracias representativas dependem da delegação de poder realizada pelos eleitores quando escolhem seus representantes. Além disso, Dahl discute o problema das regras da democracia em sistemas federalistas, como o americano. Ele mostra que existe uma distorção da representação nos sistemas federalistas nos quais indivíduos podem ser eleitos devido às regras eleitorais, mas não devido à vontade dos eleitores. No Brasil, por exemplo, a distribuição de cadeiras nos parlamentos estaduais depende do quociente eleitoral obtido pelos par-

\footnotetext{
${ }^{2}$ Em outro texto, parte dessa análise de Robert Dahl foi apresentada. O propósito desse texto era compreender de que forma as transformações recentes da democracia tornaram as chamadas "abordagens cognitivas" relevantes no campo da análise de políticas públicas. Essas abordagens atribuem papel fundamental às ideias e ao conhecimento no processo de produção de políticas públicas. Conferir Pereira, 2014, pp. 116-118.
} 
tidos nas eleições. Esse quociente é calculado de acordo com a votação de cada partido nas eleições que determinará, por sua vez, o número de cadeiras a que ele terá direito. Então, se um candidato obtém um número expressivo de votos, ele poderá ajudar seu partido a obter um número $\mathrm{X}$ de cadeiras. Dessa forma, podem ser eleitos candidatos com pequena votação, mas favorecidos por um colega de partido que foi capaz de obter votação expressiva. Esse tipo de distorção produz o que Dahl chama de violação da representação que se forma por causa da adoção de regras necessárias ao funcionamento do federalismo, mas que não produzem resultados eleitorais compatíveis com a vontade dos eleitores.

Em síntese, Dahl se manifesta cético com relação à capacidade das instituições políticas supranacionais possibilitarem maior participação dos cidadãos. A internacionalização da democracia, segundo ele, poderia causar mais violações da representação como ocorrem nos sistemas federalistas. O distanciamento dos indivíduos em relação às instituições políticas supranacionais aumentaria, impossibilitando a accountability dos policy makers. Essa accountability é problemática no plano nacional e será mais problemática ainda no plano internacional, mesmo que os sistemas políticos transnacionais sejam fortalecidos.

Esse mesmo ceticismo com relação à possibilidade de democratização das instituições políticas supranacionais é reiterado por Dahl em outro artigo (cf. Dahl, 1999). Para explicar os motivos pelos quais ele não considera que as instituições e organizações internacionais possam ser democráticas, ele examinou diversos aspectos da democracia. A democracia representativa lida, com dificuldades, no que se refere à delegação de poder. A extensão da delegação nas democracias é considerável, gerando problemas para o exercício do controle eficaz dos cidadãos sobre o processo de tomada de decisões. Quanto menor a unidade política (cidade, Estado), mais eficaz poderá ser a capacidade de controle dos cidadãos. O problema continua sendo de escopo. Dahl considera que a eficácia ou as possibilidades de controle dos cidadãos sobre a tomada de decisões são reduzidas quando se amplia a unidade política. Se existem dificuldades para os cidadãos controlarem decisões na esfera doméstica, essas dificuldades são amplificadas quando se examinam as instituições e organizações internacionais. Por isso, ele considera improvável a realização da democracia fora do espaço nacional, mesmo reconhecendo a existência de temas cujo tratamento precisa envolver um nível de decisão acima do Estado nacional.

O problema principal, segundo Dahl, diz respeito à delegação de poder necessária e inevitável na política internacional. Instituições supranacionais e organizações internacionais possuem funções e competências cada vez mais importantes, dada a crescente interdependência econômica e política característica do processo de globalização. Essas funções e competências, por sua vez, foram estabelecidas depois da Segunda Guerra Mundial, mas se alargaram ao mesmo tempo em que assuntos específicos e processos deixarem de ser da competência exclusiva dos Estados. Mas Dahl pergunta: será possível transpor ideias e práticas de um governo democrático para as organizações internacionais? A resposta a essa questão pode gerar perspectivas otimistas ou mais céticas a essa questão. Dahl responde negativamente. Para ele, não é possível tornar a tomada de decisões democrática no âmbito da política internacional (Dahl, 1999, p. 23).

Além disso, Dahl (1999, p. 20) considera que existem diferentes definições sobre o significado da democracia. Ela pode ser considerada a partir de dois pontos de vista: $1^{\circ}$ ) como um sistema de controle popular sobre políticas e decisões governamentais; $2^{\circ}$ ) como um sistema de direitos fundamentais. O primeiro ponto de vista é mais utilizado. Nele, a democracia é vista como um governo do povo, como um governo do Estado que deve ser responsivo e responsável perante o povo. O governo é uma autoridade soberana capaz de decidir importantes questões políticas diretamente ou por vias indiretas por meio de representantes escolhidos nas eleições. No segundo ponto de vista, a democracia é vista como um conjunto de direitos divididos em dois tipos principais: $(i)$ os direitos, as liberdades e as oportunidades por meios das quais se realiza o controle popular das instituições democráticas. Enquadram-se nesse tipo as liberdades de expressão e de reunião; (ii) conjunto de liberdades, direitos e oportunidades que não está relacionado ao funcionamento das instituições democráticas, tais como os direitos de propriedade, de privacidade, de sobrevivência, de nãodiscriminação e afins. 
É certo que decisões políticas tomadas no âmbito das organizações internacionais afetam a vida de muitos cidadãos. Elas são importantes espaços de deliberação sobre assuntos do interesse geral da comunidade internacional, tais como direitos humanos, meio ambiente e processos econômicos, dentre outros. Dahl considera, no entanto, que elas não são democráticas, mas sugere pensar em algumas alternativas para que sejam minimamente responsáveis perante as populações dos países. Ele (1999, pp. 33-34) sugere que as OIGs devam ser tratadas como sistemas burocráticos de negociação nos quais os líderes desses sistemas agem como governantes em regimes autoritários, isto é, não podem ignorar por completo as opiniões e desejos dos governados. Por serem sistemas burocráticos de negociação, é preciso aceitar os custos para a democracia em nome das vantagens da cooperação obtidas por meio das organizações internacionais. Dahl aponta a existência do déficit democrático na União Europeia que seria o custo provável de todos os governos internacionais (Dahl, 1999, p. 34). Assim, se necessidades humanas requerem a gestão de uma organização internacional, devemos reconhecer os aspectos antidemocráticos dessa gestão sem perder de vista a necessidade de formular propostas para uma maior democratização dos processos e das atividades das OIGs.

As dificuldades residem na definição dos critérios e dos padrões a partir dos quais podemos avaliar as tentativas de democratização das organizações internacionais. Essas tentativas podem ser observadas, por exemplo, no Banco Mundial, que desenvolveu um mecanismo de accountability - o Painel de Inspeção ${ }^{3}$, criado em 1993 - e copiado por outras instituições financeiras internacionais. Trata-se de um mecanismo que pretende criar condições para que as populações afetadas por projetos financiados pelo Banco Mundial possam se manifestar sempre que esses projetos sejam conduzidos sem seguir os procedimentos estabelecidos pelo Banco, gerando impactos sociais e ambientais indesejáveis. Nos dois artigos, Dahl identificou uma dificuldade inerente às democracias representativas - as possibilidades de controle dos cidadãos na tomada de decisões políticas. Com a ampliação do escopo da democracia (no que Dahl chamou de transnacionalização da democracia), essa dificuldade se agravou de forma considerável, pois aumentou a distância entre os indivíduos e o locus da decisão política. Essa dificuldade, por sua vez, impossibilitou o desenvolvimento democrático das instituições e organizações internacionais. Em conclusão, Dahl considera improvável a democracia fora do âmbito doméstico, sustentando, no artigo de 1994, a necessidade de aperfeiçoamento das instituições políticas nacionais como um primeiro passo importante para o fortalecimento das democracias representativas da atualidade. Frente ao ceticismo de Dahl, David Held partirá das mesmas constatações a respeito dos efeitos da globalização sobre a democracia, mas desenvolverá uma perspectiva mais "otimista" quanto às possibilidades da democracia na política internacional. Esse será o tema da próxima seção deste artigo.

\section{A perspectiva de David Held}

O "otimismo" de David Held precisa ser bem compreendido para não sugerir que sua perspectiva deixou de lado o necessário reconhecimento da existência de um déficit de accountability na política internacional. Esse déficit é, de certa forma, a tradução do problema identificado por Dahl e apontado na seção anterior deste artigo: a dificuldade de se estabelecer mecanismos de controle dos cidadãos sobre organizações e instituições internacionais. Enquanto Dahl identificou essa dificuldade e ressaltou a impossibilidade de realização da democracia na política internacional, David Held (2005) problematizou essa questão mostrando a possibilidade de desenvolvimento de uma "democracia cosmopolita" como consequência provável do avanço do processo de globalização e de seus impactos políticos e

\footnotetext{
${ }^{3}$ O Painel de Inspeção foi criado pelo Comitê Executivo do Banco Mundial para ser um veículo independente e capaz de responder as reclamações de pessoas prejudicadas por projetos financiados pelo Banco. Qualquer projeto ou programa financiado pela Associação Internacional de Desenvolvimento (AID) e pelo Banco Internacional de Reconstrução e Desenvolvimento (BIRD) - instituições financeiras do Banco Mundial - está sujeito aos pedidos de inspeção ou reivindicações realizadas por qualquer grupo capaz de mostrar que vive no local onde o projeto é desenvolvido e tem probabilidade de ser afetado ou prejudicado por ações desse projeto. Para responsabilizar o Banco Mundial, é necessário mostrar que o projeto gerou impactos sociais e ambientais resultantes de falhas dos procedimentos e ações do Banco. O pedido pode ser apresentado em qualquer idioma, por uma ONG local ou por um representante. Para mais informações sobre o Painel de Inspeção e sua influência sobre outras instituições financeiras internacionais, cf. Banco Mundial, 2012 e 2013.
} 
econômicos correlatos. Held (2005) afirmou que a política moderna assentou-se na ideia de Estado moderno e de um sistema de accountability baseada no Estado. No entanto, segundo ele, essa ideia não é mais suficiente para nos ajudar a compreender a forma adequada de accountability democrática na era global. Retomaremos esse ponto mais adiante nesta seção do artigo.

O problema inicial formulado por David Held (1991) em sua análise diz respeito à deficiência das visões tradicionais sobre a democracia, incapazes de discutir as implicações, para os regimes democráticos, da dinâmica da economia mundial, do rápido crescimento das ligações transnacionais e das grandes mudanças da natureza do direito internacional. Held sustentou que a teoria moderna do Estado soberano partiu do pressuposto de uma comunidade nacional que governa a si própria e determina seu futuro. No entanto, no contexto da globalização, decisões políticas tomadas no interior de um Estado podem ter implicações sobre a vida de cidadãos localizados em outros Estados. Não é mais possível falar em uma comunidade nacional, segundo ele, que consegue programar, com exclusividade, suas ações e decisões políticas, por causa da natureza das interconexões econômicas e políticas globais. (Held, 1991, p. 152).

Para Held, a interconexão global das decisões e dos resultados políticos levantou questões centrais a respeito de categorias da teoria clássica da democracia e de suas variantes contemporâneas. Nas democracias, o consenso é visto como o princípio indiscutível do governo legítimo. A ideia de consenso e as bases relevantes do acordo voluntário, como circunscritas a um território delimitado do Estado nacional, precisam ser colocadas em discussão frente às interconexões nacionais, regionais e globais. Em virtude disso, surgem questões fundamentais suscitadas por Held: necessita-se o consenso de quem? Requer-se o acordo de quem? Quem deve participar justificadamente de decisões relativas à localização de um aeroporto ou à construção de uma usina nuclear? Qual é a base de decisão relevante (local? Nacional? Regional? Internacional?)? Perante quem os responsáveis pela decisão precisam prestar contas? O que acontece com a legitimidade quando decisões que afetam um grande número de pessoas são tomadas em unidades políticas sem a participação democrática efetiva? As fronteiras territoriais constituem os limites de inclusão ou exclusão dos indivíduos da participação em decisões que afetam suas vidas. (conferir Held, 1991, pp. 153-154). Em síntese, afirma Held,

as interconexões regionais e globais contestam a maneira tradicional de resolver no plano nacional questões centrais da teoria e da prática da democracia. O próprio processo de governo parece 'escapar às categorias' do Estado-nação. As implicações desse fenômeno são profundas, não só para as categorias de consenso e legitimidade, mas para todas as ideias-chave do pensamento democrático: a natureza da base político-territorial do processo político (constituency); o significado da responsabilidade das decisões políticas (accountability); a forma e alcance da participação política; e enfim, a relevância do Estado-nação como guardião dos direitos e deveres dos cidadãos no momento em que ele se vê às voltas com relações e processos nacionais e internacionais desestabilizadores. (Held, 1991, p. 154; sem grifos no original)

Do seu texto emergem, pelo menos, três pontos importantes. O primeiro deles diz respeito às possibilidades limitadas de participação dos indivíduos de um país na construção de decisões políticas de outro país. No entanto, a interconexão entre os países tornaria essa participação necessária, tendo em vista que as decisões políticas do Estado A podem afetar a vida das populações dos Estados B e C. A crescente interdependência econômica e política do contexto atual tornou relevante a observação do que se passa em todos os países, pois acontecimentos de um país podem afetar outros países. É o que constataram Robert Keohane e Joseph Nye (2001) em 1977, quando publicaram Power and Interdependence. Trata-se de um processo irreversível com consequências políticas e econômicas importantes. Para Held, os desenvolvimentos internacionais recentes são diferentes dos que podem ser observados em outras épocas históricas. Trata-se de um desenvolvimento que integra o processo de globalização que envolve, pelo menos, dois fenômenos distintos: (i) sugere que a atividade política, econômica e social tem cada vez mais um alcance mundial; e (ii) sugere que a interação e interconexão entre Estados e sociedades têm-se intensificado. A intensidade das conexões entre sociedades tornou relevante a atuação de novos atores internacionais, entre os quais, as organizações não-governamentais (ONGs), os movimentos sociais transnacionais e o próprio indi- 
víduo tornou-se um ator internacional cujo papel não pode mais ser desconsiderado na análise da política internacional contemporânea, como sugere James Rosenau (1992).

As conexões que ligam sociedades nacionais, conhecidas como relações transnacionais, reduzem a autonomia e a independência do Estado-nação, conforme apontou, também, Robert Dahl na seção anterior deste artigo. No entanto, não significa que o Estado-nação desaparecerá ou será absorvido por organizações internacionais ou por instituições políticas supranacionais, pelo menos por enquanto. Esse é o segundo ponto que pode ser destacado da análise de David Held. Em termos práticos, a redução da autonomia do Estado-nação implica algumas consequências importantes sobre a gestão de diversos assuntos que afetam a vida dos indivíduos. Held lista, pelo menos, cinco questões importantes decorrentes da redução da autonomia do Estado, a saber: $(i)$ a redução da eficiência de instrumentos políticos dos governos utilizados para controlar atividades dentro e fora dos territórios nacionais; (ii) a expansão das forças e interações transnacionais reduzem e restringem a influência dos governos sobre as atividades de seus cidadãos; (iii) as atividades e as responsabilidades do Estado nacional não podem mais ser realizadas sem a colaboração internacional de outros atores estatais e não-estatais; (iv) como consequência da questão anterior, os Estados aumentam o grau de integração política com outros Estados e intensificam processos de negociação e de criação de arranjos e instituições multilaterais capazes de controlar os efeitos desestabilizadores decorrentes do desenvolvimento das interconexões; $(v)$ a expansão crescente de instituições, regimes e organizações internacionais que formam a base da governança global. (cf. Held, 1991, pp. 159-160). Em síntese,

a nova política global - envolvendo, entre outras coisas, processos de tomada de decisão multiburocráticos no interior das burocracias governamentais e internacionais e entre elas; envolvendo processos políticos desencadeados por forças transnacionais e envolvendo, enfim, novas formas de integração multinacional entre Estados - criou um quadro no qual e através do qual os direitos e obrigações, poderes e capacidades dos Estados foram redefinidos. As capacidades estatais foram ao mesmo tempo reduzidas e alargadas, permitindo ao Estado o cumprimento de uma série de funções que já não podem ser mantidas senão em conexão com relações e processos globais. (idem; sem grifos no original)

A redução da autonomia do Estado é uma importante consequência do processo de globalização, com implicações fundamentais sobre a democracia no plano doméstico e mesmo internacional. O desafio das democracias representativas, conforme apontou Dahl, era conseguir desenvolver mecanismos de accountability capazes de permitir o controle dos cidadãos sobre o processo decisório e sobre o comportamento dos policy-makers. Esse desafio se transfere, num grau de complexidade muito maior, para a política internacional. Para Held, as mudanças globais estão em curso e aumentam, de forma considerável, a importância da governança global que se desenvolve por meio de organizações e regimes internacionais e por intermédio, ainda, de processos de integração regionais. É o que se pode observar quando se examina, com atenção, as questões $i i i, i v$ e $v$ apresentadas no parágrafo acima. Se Estados tiveram seu papel redefinido por causa das crescentes interconexões globais, então é preciso reconhecer o desafio de tornar as organizações e instituições internacionais mais democráticas, tendo em vista que se tornaram locus importantes do processo de tomada de decisões políticas.

Held reconhece, no entanto, que o impacto dos processos globais varia de acordo com as condições internacionais e nacionais que podem produzir efeitos diversos de acordo com as características dos Estados nacionais. Algumas condições podem determinar esses efeitos, tais como a posição do Estado-nação no sistema internacional, a posição dentro de blocos de poder e as relações entre cada Estado e as organizações internacionais.

O grau de integração dos Estados à economia mundial, por exemplo, é muito diferente; em consequência, em alguns países a política doméstica será fortemente influenciada pelos processos globais, enquanto em outros os fatores regionais ou nacionais serão sempre os fatores mais importantes. (Held, 1991, p. 164)

Para Held, a globalização não implica restrições à política. Na prática, a globalização implicaria expansão da atividade política. A globalização não apenas desperta ou reforça uma significativa politi- 
zação de uma variedade crescente de áreas, mas essa politização é acompanhada por um extraordinário desenvolvimento de arenas institucionalizadas e redes de mobilização política, processos decisórios e atividades regulatórias que transcendem a jurisdição política nacional. Trata-se de uma expansão da capacidade para a atividade política e para o exercício da autoridade política. No entanto, alerta o autor, não se pode ignorar os diversos desafios colocados pela globalização política e econômica ao processo de elaboração de políticas públicas em seus diversos níveis (Held, 2005, p. 368).

A resolução de problemas no nível global enfrenta um número de dificuldades abordadas pelo autor. Em primeiro lugar, não há uma divisão clara de trabalho entre um conjunto variado de agências governamentais internacionais. As funções, muitas vezes, se sobrepõem, mandatos frequentemente entram em conflito e metas e objetivos frequentemente ficam desfocados. (idem). Uma segunda dificuldade relatada pelo autor diz respeito à inabilidade das agências internacionais para elaborar soluções de problemas coletivos quando confrontadas com a divergência sobre os objetivos, os meios, os custos etc. Isto leva a uma situação na qual o custo da inação é maior do que o custo de realização de uma ação. (Held, 2005, p. 369).

Uma terceira dificuldade diz respeito ao que o autor chama de déficit de accountability, que estaria ligado a duas dificuldades adicionais inter-relacionadas. Esse é o terceiro ponto que emerge das observações de Held. A primeira delas refere-se aos desequilíbrios de poder entre os Estados nacionais, e entre estes e os atores não-estatais na definição e elaboração de políticas públicas globais. Órgãos multilaterais precisam ser totalmente representativos dos Estados que estão envolvidos neles, mas raramente o são. A segunda refere-se à efetividade da representação de cada Estado dentro das organizações internacionais. O fato de um Estado ter assento na mesa de negociações em uma OIG importante ou em uma grande conferência não assegura uma representação efetiva, segundo Held (2005). Há disparidades no exercício da representação formal, entre países ricos, que possuem uma delegação formada por uma equipe técnica preparada para assessorar a decisão, e os países pobres que, por vezes, precisam, inclusive, compartilhar uma delegação com outros Estados nas mesmas condições. Por fim, muitas pessoas estão envolvidas em problemas políticos globais que as afetam, mas são excluídas das instituições políticas e das estratégias necessárias para o enfrentamento desses problemas.

Em conclusão, a abordagem de Held sugere que as organizações e instituições internacionais se tornaram locus importantes da tomada de decisões políticas. Então, deveriam estar sujeitas às cobranças e às pressões internacionais para se tornarem mais transparentes e responsáveis perante os públicos afetados por suas decisões. Por mais que reconheça a existência de mecanismos de prestação de contas de algumas das principais organizações internacionais (como o Fundo Monetário Internacional e a Organização do Tratado do Atlântico Norte), Held (1991) indaga sobre a natureza da responsabilidade dessas organizações perante os cidadãos comuns dos Estados nacionais nos quais elas operam. Held considera possível questionar as bases democráticas e a legitimidade dessas organizações. Held argumenta que, muitas vezes, decisões rotineiras e extraordinárias dos representantes dos Estados dentro das OIGs afetam cidadãos de países que não tiveram oportunidade de interferir sobre essas decisões. Além disso, a ordem internacional estruturada por agências e forças internacionais impossibilita o controle mínimo dos cidadãos sobre as decisões tomadas dentro dessa ordem. Nesse ponto, Dahl manifestou uma preocupação semelhante à de David Held: as dificuldades de se desenvolver mecanismos de accountability democrática no âmbito das organizações e instituições internacionais.

Mas o suposto "otimismo" de David Held aparece nas suas propostas cujo propósito era contornar o problema do déficit de accountability apontado por ele e reforçado em outro artigo (cf. Held, 2005). Entre essas propostas, é possível destacar a defesa do princípio da autonomia democrática, que pode ser definido nas palavras do autor:

os indivíduos devem usufruir de direitos iguais (bem como, por isso mesmo, assumir deveres iguais) no quadro social geral em que as oportunidades abertas a eles são geradas e limitadas; isto é, eles devem ser livres e iguais na determinação das condições da sua própria existência, desde que não mobilizem aquele quadro de modo a negar os direitos de outros. (Held, 1991, p. 186; grifado no original)

Para realizar esse princípio, é necessário realizar a democracia no interior de uma rede de forças e relações internacionais entrecruzadas. Esse seria o significado da democratização nos tempos de globa- 
lização (cf. Held, 1991, p. 191). Held sugere, ainda, que as questões que escapam ao controle dos Estados sejam decididas no âmbito de um quadro regional ou global ampliado. Trata-se de uma "mudança dos limites territoriais dos sistemas de responsabilidade política" (idem). Ele sugere, por fim, uma articulação das comunidades políticas territorialmente delimitadas com agências, associações e organizações-chave do sistema internacional de modo a tornar esse sistema parte de um processo democrático. Ao mesmo tempo, agências, associações e organizações deveriam adotar, em seu modus operandi, uma estrutura de regras e princípios compatível com os da autonomia democrática. (ibidem).

O que David Held está sugerindo, na verdade, é o desenvolvimento de um processo global de consulta e deliberação, organizado em níveis, que representaria, segundo ele, a melhor possibilidade de criação de uma estrutura de governança global mais responsável e sustentável. Três questões precisam ser abordadas nesse sentido, segundo ele: $(i)$ quem será representado, governos ou cidadãos? (ii) qual será o princípio de representação, um estado, um voto, representação proporcional ou uma mistura de ambos? e (iii) qual será o âmbito apropriado e os limites de ação da Assembleia Global (formada por indivíduos eleitos em seus países)? (cf. Held, 2005, p. 384, nota 37). Essa proposta esbarra, no entanto, em dificuldades resultantes da natureza da política internacional que permanece caracterizada pelas disparidades de poder entre os Estados e pelas assimetrias econômicas entre eles. As disparidades e assimetrias afetam a ONU (Organização das Nações Unidas) e sua agenda, que permanece suscetível às influências dos interesses dos Estados mais poderosos.

Assim, embora reconheça os limites para a realização da democracia na política internacional, Held apresenta algumas sugestões que poderiam tornar as organizações e instituições internacionais mais responsáveis perante os públicos afetados pelas decisões tomadas por elas. Nessas sugestões, traçadas em linhas bem gerais aqui, é possível perceber a preocupação do autor com a tentativa de aproximar os indivíduos das instituições e organizações, tentando contornar posições céticas como a de Robert Dahl, que não reconhece a possibilidade da democracia na política internacional. Nas considerações finais, serão destacadas as contribuições dos dois autores para a reflexão sobre o significado da democracia no contexto da globalização.

\section{Considerações Finais: As contribuições do "Ceticismo" e do Cosmopolitismo}

Robert Dahl e David Held destacaram, em suas análises, as transformações recentes das relações internacionais, procurando entender de que forma essas transformações geraram impactos sobre a capacidade dos Estados de gerir diversos temas que afetam a vida dos cidadãos. Ambos concordaram que há uma redução da autonomia do Estado nacional, o que não significa dizer que os Estados tendem, de imediato, a ser substituídos por unidades políticas maiores e mais abrangentes formadas por instituições e agências políticas supranacionais. Nesse sentido, o processo de integração europeu sintetiza as constatações dos dois autores. Nele se pode observar, ao mesmo tempo, o aumento da importância de instituições internacionais e a redefinição do papel dos Estados que preservam, ainda, autoridade e capacidade de deliberar sobre a cessão ou não de parcelas de seu poder para essas instituições. O processo europeu sintetiza bem as considerações dos dois autores, também, quando examinamos a coexistência de instituições políticas intergovernamentais com as supranacionais. Nas primeiras instituições, os Estados preservam capacidade de decisão na medida que são representados por membros dos seus executivos nacionais enquanto a principal instituição supranacional europeia (o Parlamento) é formada por membros eleitos pelos cidadãos europeus. A natureza intergovernamental permanece na União Europeia apesar dos avanços institucionais realizados no curso do desenvolvimento histórico deste processo, iniciado após o final da Segunda Guerra Mundial e intensificado mais recentemente no contexto da globalização. As principais organizações internacionais são dominadas pelos Estados e os cidadãos têm poucas possibilidades de interferir diretamente sobre as decisões tomadas dentro delas.

As transformações observadas no contexto internacional recente alteram as condições do desenvolvimento das democracias no espaço doméstico dos Estados. Essa é uma das principais contribuições dos autores para a análise do significado da democracia em tempos de globalização. Estas transformações levantam problemas maiores para o funcionamento das instituições e práticas dos regimes democráticos. Por exemplo, como é possível pensar a accountability nos planos doméstico 
e internacional, considerando que o processo decisório sobre questões cruciais da vida dos cidadãos não é mais exclusividade dos governos nacionais? Esses governos precisam levar em consideração, ainda, os efeitos gerados pelas interconexões globais e por processos econômicos e sociais que atravessam as fronteiras nacionais e, por vezes, não estão sujeitos aos mecanismos de controle dos Estados. É o caso, por exemplo, de uma parcela significativa do comércio internacional (algo em torno de 50\%) que se processa entre as filiais de grandes corporações transnacionais. (cf. Martins, 1999). É o caso, também, dos fluxos de capital financeiro que passaram a circular com mais liberdade devido à desregulamentação, iniciada nos anos 1970.

O déficit de accountability da política internacional é uma segunda contribuição importante de Dahl e Held. No plano doméstico, a accountability é problemática, conforme apontou Dahl na primeira seção deste artigo. Guillermo O’Donnell (1998) mostrou como ela é problemática ao analisar a situação de países da América Latina que adotaram regimes democráticos recentemente. Se ela é problemática no plano doméstico, é ainda mais complicada quando observamos as instituições e organizações internacionais, especialmente essas últimas que desenvolveram esforços para tentar ser mais transparentes e responsáveis por meio de políticas de transparência e por intermédio de mecanismos de accountability. Esses esforços, no entanto, foram insuficientes para resolver o déficit de accountability. Esses esforços, no entanto, foram insuficientes para resolver o déficit de accountability. E continuarão a ser insuficientes, pois as organizações internacionais não foram submetidas a processos de reforma capazes de adequá-las, seja às características atuais da política internacional, seja às mudanças observadas no desenvolvimento da democracia contemporânea. Para que tais mecanismos possam ser adequados, as organizações internacionais precisam resolver um problema fundamental relativo ao impacto da distribuição de poder da política internacional sobre seus processos de tomada de decisão política. Importantes organizações internacionais não alteraram, ainda, processos não democráticos de tomada de decisão política, como acontece no principal órgão das Nações Unidas, que é o Conselho de Segurança, no qual prevalece a utilização do poder de veto. Esse poder permite que os cinco membros permanentes ${ }^{4}$ possam vetar, de acordo com sua vontade, decisões tomadas dentro do Conselho de Segurança. Outras, como o Banco Mundial e o Fundo Monetário Internacional (FMI), tomam decisões de acordo com a influência exercida pelos países financiadores dessas OIGs. Por isso, enquanto as organizações internacionais não forem reformadas ou redefinidas, permanecerão sendo espaços nos quais continuarão se expressando as relações de poder existentes na política internacional contemporânea. Dessa forma, não será possível viabilizar qualquer proposta de democracia nos termos do cosmopolitismo de Held. E, nesse sentido, torna-se adequada a crítica de Robert Dahl, segundo a qual a gestão das OIGs não é, por natureza, orientada por motivações democráticas. Essa gestão pode se tornar democrática na medida que as relações de poder dentro das OIGs sejam alteradas, aumentando a participação de mais Estados e de atores nãoestatais, interessados na tomada de decisões políticas dentro delas. Para isso, é necessário o desenvolvimento e o aprofundamento de projetos de reforma dessas organizações.

Em síntese, as contribuições de Held e Dahl dimensionaram os desafios atuais da democracia, que ganharam contornos mais problemáticos, seja pela redefinição do papel dos Estados, seja pela natureza crescentemente complexa dos temas que são objeto, hoje, da tomada de decisões políticas nos âmbitos doméstico e internacional. Essas contribuições permitiram gerar uma reflexão a respeito da possibilidade da democracia na política internacional. Essas possibilidades estão limitadas, no momento, pela necessidade de se construir novos arranjos institucionais no âmbito internacional, tornando as principais OIGs mais democráticas ou, no mínimo, menos suscetíveis às influências das relações de poder da política internacional. Neste momento, o desafio maior é o de desenvolver tal arranjo para torna-lo mais compatível com as características da realidade internacional contemporânea. No momento atual, projetos de reforma das OIGs são constantemente adiados ou postergados, retardando o enfrentamento desse desafio. Assim, apesar das divergências que separam Held e Dahl, suas contribuições são relevantes ao possibilitarem reflexões sobre esse desafio complexo do mundo contemporâneo.

\footnotetext{
${ }^{4}$ Estados Unidos, Reino Unido, França, Rússia e China.
} 


\section{REFERÊNCIAS}

Banco Mundial. (2012). Citizen-Driven Accountability for Sustainable Development. Giving Affected People a Greater Voice - 20 Years On. Junho de 2012. Disponível em: ewebapps.worldbank.org/apps/IP/IPPublications. Acesso em: 04/06/2014.

- (2013). Annual Report - The Inspection Panel - 2012-2013. Disponível em: ewebapps.worldbank.org/apps/IP/IPPublications. Acesso em: 04/06/2014.

Dahl, R. (1994). A Democratic Dilemma: System Effectiveness versus Citizen Participation. Political Science Quarterly, 109, 23-34.

- (1999). Can International Organizations be Democratic? A Skeptic's View. Em I. Shapiro e C. Hacker- Cordón (Ed.), Democracy's Edges. Cambridge: Cambridge University Press.

Grant, R. W. e Keohane, R. (2005). Accountability and Abuses of Power in World Politics. The American Political Science Review, 99(1), 29-43.

Held, D. (1991). A democracia, o Estado-nação e o sistema global. Lua Nova, 23, 145-194.

- (2005). Democratic Accountability and Political Effectiveness from a Cosmopolitan Perspective. Em D. Held e M. Koenig-Archibugi (Ed.), Global Governance and Public Accountability. Blackwell Publishing.

Keohane, R. O. e Nye, J. S. (2001). Power and Interdependence. New York: Longman.

Martins, L. (1999). Novas dimensões da "Segurança Internacional". Em G. Dupas, T. Vigevani (Ed.), O Brasil e as novas dimensões da segurança internacional. São Paulo: Editora AlfaOmega/FAPESP.

Moravscik, A. (2004). Is There a "Democratic Deficit" in World Politics? A framework for Analysis. Government and Opposition - An International Journal of Comparative Politics, 39(2), 336-363.

O’Donnell, G. (1998). Accountability horizontal e novas poliarquias. Lua Nova, 44, 27-54.

Pereira, A. E. (2014). Políticas públicas e democracia. Em T. I. Cianciarullo, I. Panhoca, L. M. de M. Bonini (Ed.), Políticas Públicas: Estudos e casos. São Paulo: Editora Ícone.

Rosenau, J. (1992). Citizenship in a Changing Global Order. Em J. Rosenau, E.-O. Czempiel (Ed.), Governance Without Government: Order and Change in World Politics. Cambridge: Cambridge University Press.

União Europeia. (2014). Tratados da UE. Disponível em: http://europa.eu/eu-law/decisionmaking/treaties/index_pt.htm; Acesso em 12/07/2014.

\section{SOBRE O AUTOR}

Alexsandro Eugenio Pereira: Professor dos Programas de Pós-Graduação em Ciência Política e em Políticas Públicas da Universidade Federal do Paraná; Coordenador do Núcleo de Pesquisa em Relações Internacionais da Universidade Federal do Paraná (NEPRI/UFPR) (www.nepri.ufpr.br); Editor-chefe da Revista Conjuntura Global do Programa de Pós-Graduação em Ciência Política da UFPR (www.conjunturaglobal.ufpr.br). 